\title{
Anxiety, Depression and Academic Performance: A Study Amongst Portuguese Medical Students Versus Non- Medical Students
}

\section{Ansiedade, Depressão e Performance Académica: Um Estudo em Estudantes Portugueses de Medicina Versus Estudantes de Outros Cursos}

\author{
João MOREIRA DE SOUSA ${ }^{1}$, Cátia A. MOREIRA², Diogo TELLES-CORREIA ${ }^{3}$ \\ Acta Med Port 2018 Sep;31(9):454-462 - https://doi.org/10.20344/amp.9996
}

\section{ABSTRACT}

Introduction: The aim of the study is to assess the prevalence of anxiety and depressive symptoms in Portuguese medical students compared to students of other faculties, and the possible impact those symptoms have on academic performance.

Material and Methods: A cross-sectional study was conducted in a sample of 750 students: 512 medical students and 238 nonmedical students. All students anonymously completed a socio-demographic survey and the Hospital Anxiety and Depression Scale (HADS). Statistical analysis was performed using the chi-square test, Mann-Whitney test, Spearman correlation coefficient or KruskalWallis test.

Results: We found a prevalence of $21.5 \%(n=161)$ for anxiety symptoms and $3.7 \%(n=28)$ for depressive symptoms. Being a medical student was more significantly associated with symptoms of anxiety $(p=0.034)$ compared with other students. Depressive symptoms were slightly associated with poor academic performance $(p<0.01)$. A percentage of $59.6 \%(n=96)$ of students with anxiety symptoms and $46.4 \%(n=13)$ of students with depressive symptoms did not seek medical or psychological care at that time.

Discussion: Medical students in this sample seem to have more symptoms of anxiety, possibly explained by a higher number of female students in that sample. Depressive symptoms could be associated with poor academic performance in both groups, but an evident correlation was not established.

Conclusion: Considering the high levels of anxiety symptoms, the possible impact of depressive symptoms in academic performance and the lack of psychiatric or psychological follow-up reported in this study, it is urgent to develop adequate means of support to improve students' well-being and mental health.

Keywords: Academic Performance; Anxiety; Depression; Stress, Psychological; Students, Medical

\section{RESUMO}

Introdução: Este estudo avalia a prevalência da sintomatologia de ansiedade e depressão em estudantes portugueses de Medicina versus estudantes de outros cursos e uma eventual associação destes sintomas com alterações na performance académica.

Material e Métodos: Realizou-se um estudo transversal com 750 alunos: 512 de Medicina e 238 de outros cursos. Todos preencheram anonimamente um questionário sócio-demográfico e a escala Hospital Anxiety and Depression Scale (HADS). A análise estatística foi efetuada utilizando o teste qui-quadrado, teste de Mann-Whitney, correlação de Spearman ou teste de Kruskal-Wallis.

Resultados: Observou-se uma prevalência de sintomas ansiosos de 21,5\% ( $n=161)$ e de sintomas depressivos de 3,7\% ( $n=28)$. Os alunos de Medicina estiveram mais significativamente associados a sintomas ansiosos $(p=0,034)$ comparado com alunos de outros cursos. Os sintomas depressivos parecem estar mais associados a má performance académica $(p<0,01) .59,6 \%(n=96)$ dos alunos com sintomatologia ansiosa ou e $46,4 \%(n=13)$ dos alunos com sintomas depressivos não recebeu acompanhamento psicológico ou psiquiátrico até à data.

Discussão: Os alunos de Medicina desta amostra têm maior taxa de sintomas ansiosos, possivelmente relacionado com um maior número de estudantes do sexo feminino nesse subgrupo. Os sintomas depressivos poderão afetar negativamente a performance académica de todos os estudantes, mas não foi estabelecida uma correlação evidente entre estes dois fatores.

Conclusão: Dada a elevada taxa de sintomas de ansiedade, o eventual impacto dos sintomas depressivos a nível académico e a falta de acompanhamento especializado reportada nesta amostra, é urgente criar meios adequados de apoio aos estudantes no sentido de melhorar o seu bem-estar e saúde mental.

Palavras-chave: Ansiedade; Depressão; Desempenho Académico; Estudantes de Medicina Portugal; Stress Psicológico

\section{INTRODUCTION}

Depression and anxiety disorders pose a major challenge worldwide, with considerable morbidity and mortality associated with both. Over the course of a lifetime, $20.8 \%$ of the Americans will be diagnosed with a mood disorder, while $28.8 \%$ will have (or have had) an anxiety disorder. ${ }^{1,2}$ Considering European studies, one study on depression indicates a prevalence around $8.56 \%,{ }^{3}$ while another review points to a prevalence of anxiety symptoms of $14.7 \%{ }^{4}$ The onset for these disorders occurs relatively early in the lifespan of an individual, normally before or during their reproductive period. ${ }^{5}$ Thus, it is important to understand what life events could predispose to the

1. Faculty of Medicine. University of Lisbon. Lisbon. Portugal.

2. Schizophrenia Clinic. Hospital Júlio de Matos. Lisbon Psychiatric Hospital Center. Lisbon. Portugal.

3. University Clinic of Psychiatry and Medical Psychology. Faculty of Medicine. University of Lisbon. Lisbon. Portugal.

$\square$ Autor correspondente: João Moreira de Sousa. moreiradesousa.joao@gmail.com

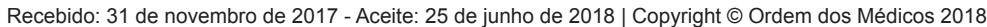


development of mental illness in such young ages. In this context, college students have been widely studied and there seems to be substantial levels of stress, anxiety and depressive symptoms among this population. Therefore, detection and treatment of this disorders at this stage could be important to prevent further damages to mental health and promote physical, psychological and professional wellbeing. ${ }^{6-8}$

Medical students are currently seen as a population under greater stress, physical and emotional demands compared to other students. In fact, different studies all over the world have demonstrated that these students have higher rates of depressive and anxiety symptoms when compared to general population within the same age range..$^{9-14} \mathrm{~A}$ recent meta-analysis focused on the prevalence of depressive symptoms and/or depression in medical students found an estimated worldwide prevalence of $27.2 \%$, while the prevalence found among European studies was between $12.8 \%$ and $21.9 \% .{ }^{15}$ These data show the urgent need to establish measures of diagnosis, support and prevention of mental health problems in this population at apparent risk.

Presently, Portugal is the second European country with the highest rate of psychiatric disorders, mainly because of its high rate of anxiety disorders. ${ }^{3,16}$ It is estimated that $16.5 \%$ of Portuguese population is suffering from an anxiety disorder, with a tendency to affect individuals at younger ages $(30.5 \%$ between 18 and 34 years versus $20.0 \%$ up to 65 years). ${ }^{16,17}$ Despite this, the issue of mental health in Portuguese University students, particularly medical students, has only recently begun to be studied. Two Portuguese studies that focus on medical students have demonstrated that this group has higher rates of stress symptoms and health risk behaviors, which create a tendency for future mental health problems and may lead to the need for psychiatric/psychological care. ${ }^{18,19}$ Another study revealed a prevalence of $6.1 \%$ of depression and $3.9 \%$ prevalence of suicidal behavior among Portuguese medical students. It is important to note, though, that a comparison with Portuguese non-medical students has not yet been performed. ${ }^{20}$

In addition to the impact of mental health in the functioning of the individual and his relationship with others, it is also important to highlight the impact of mental illness in academic performance. ${ }^{21}$ Eisenberg and coauthors reveal that between $41.2 \%$ and $44.3 \%$ of students claim that their academic performance was affected by emotional or mental problems, and $14.1 \%$ to $18.4 \%$ failed at least one academic obligation due to mental health issues. In this population, in both anxiety and depression, the overwhelming majority reported at least one functional deficit regarding their academic performance. ${ }^{22}$ In the case of medical students, in one study, borderline levels of anxiety were related to better academic results (versus lower or higher levels of anxiety) while low levels of depressive symptoms seemed to benefit the performance of medical students (versus borderline or higher levels of depression). ${ }^{23}$
For a better understanding of medical education in Portugal, it is important to summarize how it works. For this, we are considering the example of the Faculty of Medicine of the University of Lisbon (FMUL), in which we built the present study. Since the Bologna process (in which European colleges adapted their curricular plans in order to have more uniform features between them), the faculty of Medicine of the University of Lisbon changed the organization and course distribution throughout the curricular years of the medical degree. At the present time, students start with three years of the first cycle in basic sciences (which are mostly didactic, based on theoretical, laboratorial and practical classes, and other typologies such as seminars and internships), followed by two years of clinical training (with both practical and theoretical classes in a more experience-based approach) and a sixth year of curricular internship (based on supervised clinical experience in a medical facility). At the end of the curricular internship, they undergo a final exam to apply for specialist training, which they only begin after another year of professional, supervised medical experience rotating between different specialties.

To date, we found no studies comparing anxious and depressive symptoms between medical and non-medical students in Portugal. A more insightful view of the problem would enable health professionals to draw more concrete plans of action in this subgroup at apparent risk and, in the long run, reverse the growing trend of psychiatric morbidity among medical students.

In this study we intended to evaluate, within a sample of medical students in one Portuguese medical faculty, their levels of anxiety and depression symptoms and compare the results with a group of non-medical students. Finally, we asked if there could be an eventual association between levels of anxiety and/or depression and poor academic performance of all students (medical and non-medical).

\section{MATERIAL AND METHODS}

We conducted an observational, cross-sectional study during May 2015 (thus, not during the official examination period), in order to evaluate the prevalence of symptoms of anxiety and/or depression in medical and non-medical students, using the Hospital Anxiety and Depression Scale (HADS).

In this study, 761 students were involved, including 521 medical students from the Faculty of Medicine - University of Lisbon (Faculdade de Medicina da Universidade de Lisboa, FMUL), and 240 non-medical students from a different faculty (86 economics students, 81 finance students and 73 management students, all from Lisbon School of Economics and Management - Instituto Superior de Economia e Gestão, ISEG). From this point onwards, each group of students will be addressed by faculty, or 'medical students' versus 'non-medical students'.

Overall, this sample was a non-randomized, nonintentional sample (convenience sampling). The analysis aimed to include students from different curricular years - 
from $1^{\text {st }}$ to $5^{\text {th }}$ year regarding medical students, and from $1^{\text {st }}$ to $3^{\text {rd }}$ year regarding non-medical students. Sixth year medical students were not included due to difficulties obtaining an adequate sample.

The study was submitted for approval of the Ethics Committee of the Lisbon Academic Medical Centre (Centro Académico de Medicina de Lisboa, CAML). It was also approved by the Executive Council of ISEG. Each student filled an informed consent form before participating in the study.

\section{Social-demographic assessment}

The sample was characterized by: age, gender, marital status, whether they benefitted from working-student status, previous or current psychiatry or psychology followup, faculty and area of study, and curricular year. The data regarding all these parameters was self-reported by the participants. Each participant filled the social-demographic survey on paper, which was then collected directly by the authors. All the incompletely or incorrectly filled surveys were excluded from the analysis.

\section{Hospital Anxiety and Depression Scale (HADS)}

The HADS scale consists of 14 items (seven related to symptoms of anxiety and seven to symptoms of depression). Each item is assigned with a score from 0 to 3 (depending on the frequency or intensity of present symptoms). At the end, all components are added and two scores obtained (from 0 to 21 points): one for anxiety symptoms (HADSAnxiety/HADS-A) and another for depressive symptoms (HADS-Depression/HADS-D). A score lower than eight is considered within the normal range; between eight and 10 (including) is considered borderline-normal; 11 and higher scores are considered clinically relevant, corresponding to moderate or severe symptoms. ${ }^{24}$ Although this scale was originally created to evaluate symptoms in hospitalized patients, other studies have shown its applicability to the general community, including college students. ${ }^{25-30}$ The HADS has also been previously translated and validated for the Portuguese population, which allowed us to apply this instrument on our sample. ${ }^{31}$

\section{Academic performance criteria and assessment}

To best define 'academic performance', two criteria were established: the number of failed academic courses (meaning, the courses they failed and are retaking) and the current approximate curricular average grade (usually scored in a scale of 0 to 20). This data was self-reported by the participants.

\section{Statistical analysis}

Statistical analysis was performed using SPSS v22 Statistics software for Windows. In all cases a $p$ value < 0.05 was considered statistically significant.

Data on descriptive analysis will be presented in absolute and relative frequency, average, and grouped by faculty (medical students versus non-medical students).
The association between the different socio-demographic variables and each of the sub-groups by faculty was obtained using the $\chi^{2}$ test.

To test the relationship between different sub-groups per faculty and the values of HADS, it was considered that only HADS scores greater than 10 are indicative of clinically relevant (thus, potentially pathological) anxiety and/or depressive symptoms. Thus, we recorded the relative frequency of participants, per faculty, with HADS values above 10 for both parameters individually (anxiety and depression), and statistical significance was established by the $\chi^{2}$ test. To investigate the association between the average absolute value of both scores within each group (medical versus non-medical students), we used the Mann-Whitney test (given the lack of normal distribution of the variables by the Shapiro-Wilk test). The same tests were used to check for Gender association with greater symptoms of anxiety or depression.

To assess how anxiety and depressive symptoms could relate with academic performance, we searched for an eventual correlation of the scores of anxiety and depression with the selected criteria for academic performance (number of failed courses and curricular average grade), using the Spearman correlation coefficient.

We also attempted to assess anxiety and depression throughout the several academic years at college. For this purpose, the average scores of symptoms of anxiety and depression were calculated for each academic year, within each college. The association between HADS scores and Current Curricular Year was settled using the Kruskal-Wallis test, given the lack of normal distribution of this variable between the several years.

Finally, we recorded the relative frequency of students with clinically relevant anxiety or depressive symptoms (with scores greater than 10 on the HADS scale) that have (or have had) psychological or psychiatric care (within each college and considering the total sample).

\section{RESULTS}

\section{Socio-demographic sample characterization}

From all 761 participants, 10 were excluded due to incomplete filling of the HADS questionnaire and one was excluded for not indicating the gender $(n=750)$. Table 1 presents the socio-demographic characteristics of the sample selected in this study. Regarding the sociodemographic characterization, a statistically significant association between faculty and gender was found ( $p=$ 0.005).

\section{HADS scores}

In this study, we found that $21.5 \%$ of all individuals had scores of HADS-Anxiety greater than 10 . As for the HADSDepression scale, $3.7 \%$ of individuals had scores higher than 10. Considering medical students alone, $23.6 \%$ had scores higher than 10 in the HADS-A scale, and there seems to be a statistically significant association between clinically relevant anxiety symptoms (HADS-A higher than 
Table 1 - Socio-demographic sample characterization

\begin{tabular}{|c|c|c|c|c|}
\hline Variable & $\begin{array}{l}\text { Medical } \\
\text { students }\end{array}$ & $\begin{array}{l}\text { Non-medical } \\
\text { students }\end{array}$ & Total & Correlation/significance ( $\chi^{2}$ test) \\
\hline n (absolute value) & 512 & 238 & 750 & ---- \\
\hline Age (average) & 21.69 & 20.39 & 21.28 & ---- \\
\hline \multicolumn{5}{|l|}{ Gender (\%) } \\
\hline Male & $34.4 \%$ & $46.2 \%$ & $38.1 \%$ & \multirow{2}{*}{ Pearson Chi-Sq 9.660; $p=0.002^{* \star}$} \\
\hline Female & $65.6 \%$ & $53.8 \%$ & $61.9 \%$ & \\
\hline \multicolumn{5}{|l|}{ Marital Status (\%) } \\
\hline Single & $97.3 \%$ & $100.0 \%$ & $98.1 \%$ & \multirow{2}{*}{ Pearson Chi-Sq 6.632; $p=0.01^{*}$} \\
\hline Married & $2.7 \%$ & $0.0 \%$ & $1.9 \%$ & \\
\hline Working students (\%) & $6.6 \%$ & $8.8 \%$ & $7.3 \%$ & Pearson Chi-Sq 1.244; $p=0.265$ \\
\hline $\begin{array}{l}\text { Previous/present } \\
\text { psychiatric/psychologist } \\
\text { follow-up (\%) }\end{array}$ & $20.1 \%$ & $21.4 \%$ & $20.5 \%$ & Pearson Chi-Sq $0.112 ; p=0.738$ \\
\hline
\end{tabular}

* significant value $(p<0.05)$; ** significant value $(p<0.01)$

Table 2 - HADS scores relation with faculty (Medical students versus Non-medical students), analyzed per gender and considering the total sample (relative frequency of students with scores higher than 10 and total average score)

\begin{tabular}{|c|c|c|c|c|}
\hline Variable & $\begin{array}{l}\text { Medical } \\
\text { students } \\
(n=512)\end{array}$ & $\begin{array}{l}\text { Non-medical } \\
\text { students } \\
(n=238)\end{array}$ & $\begin{array}{c}\text { Total } \\
(n=750)\end{array}$ & Correlation/significance ( $\chi^{2}$ test) \\
\hline \multicolumn{5}{|l|}{ Male } \\
\hline HADS-A > $10(\%)$ & $14.2 \%$ & $10.0 \%$ & $12.6 \%$ & $\chi^{2}:$ Pearson Chi-Sq 1.088; $p=0.297$ \\
\hline HADS-D > $10(\%)$ & $2.3 \%$ & $3.6 \%$ & $2.8 \%$ & $\chi^{2}:$ Pearson Chi-Sq 0.463; $p=0.496$ \\
\hline HADS-A Score average & 6.3239 & 5.7818 & 6.1154 & Mann-Whitney U Test; $p=0.245$ \\
\hline HADS-D Score average & 3.0227 & 3.3545 & 3.1503 & Mann-Whitney U Test; $p=0.278$ \\
\hline \multicolumn{5}{|l|}{ Female } \\
\hline HADS-A > $10(\%)$ & $28.60 \%$ & $22.70 \%$ & $26.90 \%$ & $\chi^{2}:$ Pearson Chi-Sq 1.648; $p=0.199$ \\
\hline HADS-D > $10(\%)$ & $4.2 \%$ & $4.7 \%$ & $4.3 \%$ & $\chi^{2}:$ Pearson Chi-Sq $0.061 ; p=0.805$ \\
\hline HADS-A Score average & 8.2530 & 7.7500 & 8.1142 & Mann-Whitney U Test; $p=0.285$ \\
\hline HADS-D Score average & 3.4048 & 3.7109 & 3.4892 & Mann-Whitney U Test; $p=0.184$ \\
\hline \multicolumn{5}{|l|}{ Total } \\
\hline HADS-A > $10(\%)$ & $23.60 \%$ & $16.8 \%$ & $21.50 \%$ & $\chi^{2}:$ Pearson Chi-Sq 4.491; $p=0.034^{*}$ \\
\hline HADS-D > $10(\%)$ & $3.5 \%$ & $4.2 \%$ & $3.7 \%$ & $\chi^{2}:$ Pearson Chi-Sq 0.213; $p=0.645$ \\
\hline HADS-A Score average & 7.5898 & 6.8403 & 7.3595 & Mann-Whitney U Test; $p=0.029^{*}$ \\
\hline HADS-D Score average & 3.2734 & 3.5462 & 3.3635 & Mann-Whitney U Test; $p=0.115$ \\
\hline
\end{tabular}

${ }^{*}$ significant value $(p<0.05)$

$10)$ and being a medical student $(p=0.034)$. The average anxiety scores are also significantly associated with faculty $(p=0.029)$, with a higher average of HADS-Anxiety scale scores in medical students. When analyzed by gender sub-groups, this association is no longer significant. Table 2 shows the relative frequency of individuals with HADS scores higher than 10, grouped by faculty (medical versus non-medical students) and considering the total population studied.

Table 3 shows the relative frequency of individuals with HADS scores greater than 10 per Gender, in each faculty (medicine versus non-medical students), and considering the total sample. It was found that there is a significant association between gender and HADS-Anxiety scores > $10(p<0.001)$ : and that $26.9 \%$ of female students had a HADS-A score greater than 10 as opposed to $12.6 \%$ of male students. There is also an association between average HADS-Anxiety scores and Gender, with higher average HADS-Anxiety scores among female students.

We also found that there are higher average Anxiety and Depression scores in the $1^{\text {st }}, 2^{\text {nd }}$ and $5^{\text {th }}$ years of medical school, and comparably lower values in the $3^{\text {rd }}$ and $4^{\text {th }}$ years. This variation, according to the Kruskal-Wallis test, is statistically significant and is mostly due to the decline in the HADS scores among the $4^{\text {th }}$ year medical students. However, in the group of non-medical students, the average anxiety score is higher in the last two academic years, whereas the depression scores are higher in the first and 
third years. For this group, the association between these variables was not statistically significant (as shown on Table 4).

\section{HADS scores and academic performance}

Medical students report higher curricular average grades (mean: 14.83 vs 13.12) and less failed courses (mean: 0.15 vs 2.86) when compared to non-medical students. As we can see in Table 5, considering the total sample, there seems to be a positive association between HADS-Depression scores and the average number of failed courses, and a negative correlation between the HADS-Depression scores and the reported average curricular grade (both associations with statistical significance; $p<0.001$ ). If we consider each faculty individually, these associations remain, but they are only statistically significant when considering the students of the Faculty of Medicine alone.

\section{Psychiatry / Psychology follow-up}

In the case of anxiety, we have found that $59.6 \%$ of students with moderate or more severe symptoms had never resorted to a doctor or psychologist. In the case of students with moderate to severe symptoms of depression, $46.4 \%$ had no psychiatric or psychological support as well. When considering each faculty individually, there is not a wide difference in the percentage of students with psychiatric or psychological counselling.

\section{DISCUSSION}

Regarding the statistical association between gender and faculty (medical versus non-medical students), this association is probably justified by the higher percentage of female students attending medical school in this sample.

Comparing the relative frequency of students with anxiety or depression symptoms in other studies, we found that the percentages obtained in this sample are relatively lower, especially regarding depressive symptoms. However, it should be noted that most of those studies used different instruments to evaluate anxiety and depression symptoms ${ }^{6-8,21}$ Even so, another study using the HADS scale and considering the same cut-off to define clinically relevant symptoms (i.e., a score higher than 10) also

Table 3 - HADS scores relation with Gender, per faculty and among the total sample (relative frequency of students with scores higher than 10 and total average score)

\begin{tabular}{|c|c|c|c|c|}
\hline Variable & $\begin{array}{c}\text { Male } \\
(n=286)\end{array}$ & $\begin{array}{l}\text { Female } \\
(n=464)\end{array}$ & $\begin{array}{c}\text { Total } \\
(n=750)\end{array}$ & Correlation/significance ( $\chi^{2}$ test) \\
\hline \multicolumn{5}{|l|}{ Medical students } \\
\hline HADS-A > $10(\%)$ & $14.20 \%$ & $28.60 \%$ & $23.60 \%$ & $\chi^{2}$ : Pearson chi-sq 13.209; $p<0.001^{* *}$ \\
\hline HADS-D > $10(\%)$ & $2.30 \%$ & $4.20 \%$ & $3.50 \%$ & $\chi^{2}:$ Pearson chi-sq 1.221; $p=0.269$ \\
\hline HADS-A score average & 6.3239 & 8.2530 & 7.5898 & Mann-Whitney U test; $p<0.001^{* *}$ \\
\hline HADS-D score average & 3.0227 & 3.4048 & 3.2734 & Mann-Whitney U test; $p=0.211$ \\
\hline \multicolumn{5}{|l|}{ Non-medical students } \\
\hline HADS-A > $10(\%)$ & $10.00 \%$ & $22.70 \%$ & $16.80 \%$ & $\chi^{2}:$ Pearson chi-sq $6.777 ; p=0.009^{\star *}$ \\
\hline HADS-D > $10(\%)$ & $3.60 \%$ & $4.70 \%$ & $4.20 \%$ & $\chi^{2}:$ Pearson chi-sq $0.162 ; p=0.687$ \\
\hline HADS-A score average & 5.7818 & 7.7500 & 6.8403 & Mann-Whitney U test; $p<0.001^{* *}$ \\
\hline HADS-D score average & 3.3545 & 3.7109 & 3.5462 & Mann-Whitney U test; $p=0.296$ \\
\hline \multicolumn{5}{|l|}{ Total } \\
\hline HADS-A > $10(\%)$ & $12.60 \%$ & $26.90 \%$ & $21.50 \%$ & $\chi^{2}$ : Pearson chi-sq 21.619; $p<0.001^{* *}$ \\
\hline HADS-D > $10(\%)$ & $2.80 \%$ & $4.30 \%$ & $3.70 \%$ & $\chi^{2}:$ Pearson chi-sq $1.127 ; p=0.288$ \\
\hline HADS-A score average & 6.1154 & 8.1142 & 7.3595 & Mann-Whitney U test; $p<0.001^{* *}$ \\
\hline HADS-D score average & 3.1503 & 3.4892 & 3.3635 & Mann-Whitney U Test; $p=0.153$ \\
\hline
\end{tabular}

** significant value $(p<0.01)$

Table 4 - HADS scores variation between curricular years

\begin{tabular}{|c|c|c|c|c|c|c|}
\hline Curricular year & $1^{\text {st }}$ & $2^{\text {nd }}$ & $3^{\text {rd }}$ & $4^{\text {th }}$ & $5^{\text {th }}$ & $\begin{array}{c}\text { Correlation/significance } \\
\text { (Kruskal-Wallis test) }\end{array}$ \\
\hline \multicolumn{7}{|l|}{ Medical students } \\
\hline Average HADS-A score & 9.2473 & 8.2976 & 7.0840 & 6.2462 & 7.8706 & $p<0.001^{* *}$ \\
\hline Average HADS-D score & 4.3871 & 3.7976 & 2.7899 & 2.6385 & 3.2235 & $p<0.001^{* *}$ \\
\hline \multicolumn{7}{|l|}{ Non-medical students } \\
\hline Average HADS-A score & 5.8710 & 7.1136 & 7.3103 & --- & --- & $p=0.145$ \\
\hline Average HADS-D score & 3.6452 & 3.2045 & 3.8506 & --- & --- & $p=0.469$ \\
\hline
\end{tabular}


Table 5 - Parameters of academic performance and their correlation with HADS score

\begin{tabular}{lcc}
\hline Faculty & No. of failed courses & Curricular average grade \\
\hline $\begin{array}{l}\text { Medical students (average) } \\
\text { Average HADS-A score } \\
\text { (Spearman correlation coefficient) }\end{array}$ & 0.15 & 14.83 \\
$\begin{array}{l}\text { Average HADS-D score } \\
\text { (Spearman correlation coefficient) }\end{array}$ & 0.083 & -0.048 \\
Non-medical students (average) & $0.113^{*}$ & $-0.117^{*}$ \\
$\begin{array}{l}\text { Average HADS-A score } \\
\text { (Spearman correlation coefficient) }\end{array}$ & 2.56 & 13.12 \\
$\begin{array}{l}\text { Average HADS-D score } \\
\text { (Spearman correlation coefficient) }\end{array}$ & 0.103 & -0.070 \\
$\begin{array}{l}\text { Total (average) } \\
\text { Average HADS-A score } \\
\text { (Spearman correlation coefficient) }\end{array}$ & 0.112 & -0.077 \\
$\begin{array}{l}\text { Average HADS-D score } \\
\text { (Spearman correlation coefficient) }\end{array}$ & 0.91 & 14.26 \\
\hline
\end{tabular}

* significant value $(p<0.05)$; ${ }^{* *}$ significant value $(p<0.01)$

showed higher average scores than this sample for students of several areas of study. ${ }^{27}$

Compared to the overall Portuguese population, students in our sample seem to have higher levels of anxiety symptoms but lower levels of depressive symptoms. This observation could go accordingly to the already documented diagnosis of anxiety disorders at younger ages (opposed to a peak of depressive disorders in older ages)..$^{16,17}$

In this study, we found a statistically significant association between gender and the HADS-Anxiety scale. Considering each college, this association seems to be slightly stronger in medical school, but is also present for non-medical students. This suggests that female students may be more affected by symptoms of anxiety than male students. This interpretation has already been made for symptoms of anxiety in female students in general and for both symptoms (anxiety and depression) among female medical students. ${ }^{3,22,23}$ Nevertheless, in our sample, the same was not verified for the HADS-Depression scale. This may be so because of the overall low percentage and absolute cases of students with HADS-Depression scores above 10.

Regarding medical students, the prevalence of both anxiety and depressive symptoms found in this sample were, in general, lower than the values found in other studies, although the results are highly variable between different populations. ${ }^{11,12,15,32}$ Regarding depressive symptoms specifically, and comparing with a recent metaanalysis, the prevalence found in the study is substantially lower $(27.2 \%$ vs $3.7 \%)$. Still, in the same meta-analysis, if we only contemplate studies using the HADS-scale and the same cut-off for depressive symptoms (>10), the overall prevalence for depressive symptoms goes down to $9.3 \% .^{15}$ However, we should consider that this meta-analysis included a much wider population from all over the world. Comparing with previous results obtained in Portuguese medical students, we found considerably higher levels of anxiety symptoms and slightly lower levels of depressive symptoms. ${ }^{20}$

As mentioned, we must keep in mind that other studies have used other instruments to evaluate symptoms of anxiety and depression. Studies also using the HADS scale demonstrated a wide variety of results, showing generally lower average HADS scores. Still, one study shows a higher percentage of students with clinically significant symptoms of depression. This specific finding may be explained by the different cut-off for 'clinically relevant' symptoms used in that study, which was a HADS-D score greater than 8 (which should be categorized as borderline-normal as proposed by the authors of HADS scale). ${ }^{15,23,25,28,30}$ This obviously affects the interpretation of the data, because there would be a higher number of students fulfilling the criteria for 'clinically significant symptoms'. In our study, we chose to stick with the original proposal made by the authors of the HADS scale. Thus, we considered only scores above 10 as clinically relevant, leaving scores between eight and 10 out of the analysis. Another study conducted in Lithuania also using a lower cut-off obtained both higher rates of moderate depression or anxiety symptoms and a higher average score of HADS. ${ }^{29}$ The higher rate of female students in this study may have inflated the scores obtained (if we consider that female gender may be a factor associated with increased anxiety and depression in students).

The association found in this sample between medical school and anxiety symptoms was already hypothesized in previous studies. This was not verified for symptoms of depression (which could also be explained by the overall low number of cases with clinically relevant symptoms). As we already mentioned above, we should consider that the high rate of female students in medical school may have raised the percentage of cases of pathological anxiety symptoms in our sample of medical students. ${ }^{12,13}$ Because of this, an exact correlation cannot be made based only on these associations. For that, we would need a more equally distributed sample regarding number and gender, and a different statistical analysis would be more suitable. 
Noting the change in average scores of anxiety and depression scales between curricular years at each college, it was perceptible that in medical school there are higher scores of anxiety and depressive symptoms in the $1^{\text {st }}$ year, followed by a gradual decrease until the $4^{\text {th }}$ year and a new rise in the $5^{\text {th }}$ year. In non-medical students, the anxiety scores increase progressively until the last year, and the depression scores are higher in the $1^{\text {st }}$ and $3^{\text {rd }}$ years. However, it should be noted that this was a cross-sectional study among students attending college at the same time (during the second semester). Also, we did not include in our sample students from the $6^{\text {th }}$ year of medical degree (curricular internship). The main reason for this was the extreme difficulty on obtaining an adequate (equally distributed) sample from this group, since they are not concentrated in only one medical institution and have very different schedules and responsibilities. Taken this into account, we cannot draw definite conclusions about the variation of anxiety and depressive symptoms throughout the medical degree. For this, a longitudinal study would be more appropriate.

Still, some considerations can be made that could contribute to justify the differences found between curricular years of medical degree. We propose that higher levels of anxiety and depression in the early years of medical school could be due to the adaptation of students to a new academic environment. There is considerably more psychological burden and much more effort is needed for the students to maintain the standards they were used to during high school. In fact, all medical students tend to be very successful during high school. Thus, adjusting to new requirements and academic effort to maintain similar high grades can affect their mental health.

The lower scores in the following years (until the $4^{\text {th }}$ year) could be justified by a gradual adjustment to a more demanding academic environment. Finally, the higher rates of anxiety and depression symptoms in the $5^{\text {th }}$ year may be due to a more demanding academic level, combined with new concerns and responsibilities to come. These include the final curricular average grade, the Master's thesis, the early clinical internship and the national exam to engage in a residency program. This may be intensified by the increasing difficulty in accessing residency in the present circumstances, in Portugal.

The negative relationship between academic performance and depressive symptoms was already known from other studies. ${ }^{22,23}$ In this sample, symptoms of depression appeared to be associated with more failed courses and lower curricular average grade. We must point out, however, that this association was only statistically significant for medical students. Also, the correlation level was too low to ascertain a definitive conclusion for the relationship between depressive symptoms and academic performance in this sample. The absence of significance in the non-medical students' group could be because the average of HADS-D score was higher when compared to medical students (although not statistically significant). In addition, both the curricular average grade and the number of failed courses are considerably worse compared to medical students. For these reasons, an association between poor performance and higher levels of depressive symptoms in this study subgroup may be missed. The fact that there wasn't a statistically significant association of anxiety with academic performance is unexpected, since the effect of symptoms of anxiety on students' performance, in other studies, is also well documented. ${ }^{22,23}$ Nevertheless, the evaluation criteria for academic performance in these other studies were different (or not known). Besides, a non-linear correlation between anxiety and academic performance has been described (as mentioned above), with better results being obtained with borderline levels of anxiety comparing with both lower or higher levels. This could also contribute to the lack of direct association and, consequently, the lack of statistical significance. ${ }^{23}$

Finally, we have also found that a considerable percentage of students with moderate or more severe symptoms of anxiety and depression were not receiving care from a psychiatrist or psychologist (59.6\% for anxiety symptoms; $46.4 \%$ considering depressive symptoms). This may be due to several factors, some of them already mentioned in other studies addressing the problem. ${ }^{33,34}$ Some students may find they are able to address the problem themselves (without the need for medical, psychological or pharmacological help), refusing to receive care from an expert for this purpose. They may also not be able to recognize the seriousness of their symptoms or the boundaries between normal and pathological anxiety or between sadness/mourning and depression, leading them to accept these symptoms as being normal or part of the academic preparation process. The costs and time typically required for proper psychiatric and/or psychological support may also be barriers that prevent students from resorting to a doctor, especially if it involves parental support or intervention (who may have to finance the treatment, thus adding the concern for non-confidentiality). Furthermore, there is still a considerable amount of stigma (both personal and from others) among young people regarding mental disorders (even among medical students in Portugal). ${ }^{35-37}$ A Portuguese study addresses yet another issue that may exacerbate the problem even further among medical students: some of them may be 'self-diagnosing' anxiety or depressive syndromes and even self-medicating (due to the knowledge they may acquire about the issue and easy access to drugs), thus avoiding discussing their symptoms with someone else and leading to lower rates of adequate medical support. ${ }^{19}$

The main limitation of this study was the discrepancy in the number of individuals of each college that participated in the study, since the availability of participants of each faculty was considerably different. Additionally, the gender distribution between the two universities was divergent (with a higher percentage of female students in the medical students group). Considering this, plus the limited number of faculties participating in the study, we cannot extrapolate 
these data to all national medical schools. Further studies should be conducted to better ascertain the prevalence of anxiety and depressive symptoms in Portuguese medical students.

Another limitation, considering the recording of sociodemographic data - including the curricular average grade, number of failed courses and psychiatric/psychological follow-up - is the fact that it was self-reported. Access to medical and curricular records would certainly offer more reliable information regarding their academic performance or previous/current mental illness. On the other hand, difficulties (both ethical and legal) would emerge with the retrieval of official curricular and/or medical records of each student in this sample. We would assume, since the participation in this study was voluntary, that the data corresponds to their true perception of the facts and as close to the truth. However, there is no way to guarantee the absolute veracity of the data obtained.

Regarding the HADS scale, it must be noted that the HADS scale only refers to both anxiety and depression symptoms 'in the past week', and this is what we tried to approach in this study. A diagnosis of an anxiety disorder or depression cannot be made based on these scores only. Other factors, such as accompanying symptoms, time of onset and day-to-day impact must be considered. It is also important to remember that this instrument was originally built to evaluate in-hospital patients, although it has already been widely used in the general community. Thus, this scale is only meant to measure the intensity or frequency of present symptoms, not to diagnose an actual mood or anxiety disorder. For that, further evaluation of each case would be necessary to establish the true intensity, duration and impact of the symptoms in the students' life.

At last, this study has not considered other factors that can induce short-term anxiety or psychological stress (thus affecting the scores obtained), such as practical classes or other regular evaluations, not occurring in the usual semester examination period.

\section{CONCLUSION}

In this study, Medical Students appear to have higher levels of anxiety symptoms when compared to nonmedical students. However, we point out the possible major influence of the higher rate of female students in the medical school population. Given the available sample, we cannot establish definitive conclusions regarding causality or straight correlations between these variables. Wider, more equally distributed samples and a different kind of statistical analysis would be necessary. Therefore, we suggest that further studies should be conducted, with more faculties involved and a more standardized sample regarding gender and number.

Although symptoms of depression showed some association with students' poor academic performance, we could not estimate how exactly these symptoms affect their performance. Again, further analysis with more exact ways to define 'good' and 'bad' performance would be more accurate in order to draw better conclusions regarding this issue.

We finally conclude that about half the students in our sample with anxious and/or depressive symptoms have not received, to the present date, psychiatric or psychological counselling. Therefore, the high prevalence of anxiety symptoms in addition to the low percentage of specialized monitoring requires a higher level of intervention and awareness from universities, faculties, teachers, family and from students themselves. The early recognition and treatment of mental disorders is essential to allow a better academic achievement and consequently a healthier adjustment to adult and working life.

\section{PROTECTION OF HUMAN AND ANIMAL SUBJECTS}

The authors declare that the research procedures were performed according to the regulations of the institution's ethics committee and the Code of Ethics of the World Medical Association (Declaration of Helsinki).

\section{CONFIDENTIALITY OF DATA}

The authors declare that they have followed the protocols of their work centre regarding the publication of data from patients.

\section{CONFLICT OF INTEREST}

No conflict of interest has been declared by any author.

\section{FUNDING}

No financial support was received by any author.

Psychiatry. 2005;62:593-602

6. Shamsuddin K, Fadzil F, Ismail WSW, Shah SA, Omar K, Muhammad NA, et al. Correlates of depression, anxiety and stress among Malaysian university students. Asian J Psychiatr. 2013;6:318-23.

7. Chen L, Wang L, Qiu XH, et al. Depression among Chinese University Students: Prevalence and Socio-Demographic Correlates. PLoS One. 2013;8:1-6

8. Ibrahim AK, Kelly SJ, Adams CE, Glazebrook C. A systematic review of studies of depression prevalence in university students. J Psychiatr Res. 2013;47:391-400.

9. Ahmed I, Banu H, Al-Fageer R, Al-Suwaidi R. Cognitive emotions: Depression and anxiety in medical students and staff. J Crit Care. 2009;24:e1-e7.

10. Dyrbye LN, Thomas MR, Shanafelt T. Systematic review of depression, 
anxiety and other indicators of psychological distress among U.S. and Canadian medical students. Acad Med. 2006;81:354-73.

11. Hope V, Henderson M. Medical student depression, anxiety and distress outside North America: a systematic review. Med Educ. 2014;48:963-79.

12. Alvi T, Assad F, Ramzan M, Khan FA. Depression, anxiety and their associated factors among medical students. J Coll Physicians Surg Pak. 2010;20:122-6.

13. Jadoon NA, Yaqoob R, Raza A, Shehzad MA, Zeshan SC. Anxiety and depression among medical students: a cross-sectional study. J Pak Med Assoc. 2010;60:699-702.

14. Khan MS, Mahmood S, Badshah A, Ali SU, Jamal Y. Prevalence of depression, anxiety and their associated factors among medical students in Karachi, Pakistan. Int J Psychol. 2006;3:583-6.

15. Rotenstein L, Ramos MA, Torre M, Segal JB, Peluso MJ. Guille C, et al. Prevalence of depression, depressive symptoms, and suicidal ideation among medical students: a systematic review and meta-analysis. JAMA. 2016;316:2214-36

16. Direção-Geral de Saúde, Lisboa - Programa Nacional de Saúde Mental \& Direção de Serviços de Informação e Análise. Portugal - Saúde Mental Em Números - 2014. Lisboa: DGS; 2014.

17. Almeida J, Xavier M, Cardoso G, et al. Estudo epidemiológico nacional de saúde mental - 1.0 Relatório; Faculdade de Ciências Médicas, Universidade Nova de Lisboa, 2013. Lisboa: FCM, UNL; 2013.

18. Loureiro E, Mclntyre T, Mota-Cardoso R, Ferreira MA. A relação entre o stress e os estilos de vida nos estudantes de Medicina da Faculdade de Medicina do Porto. Acta Med Port. 2008;21:209-14.

19. Roberto A, Almeida A. A saúde mental dos estudantes de medicina. Acta Med Port. 2011;24:279-86.

20. Coentre R, Faravelli C, Figueira ML. Assessment of depression and suicidal behaviour among medical students in Portugal. Int J Med Educ. 2016;7: 354-63

21. Bayram N, Bilgel N. The prevalence and socio-demographic correlations of depression, anxiety and stress among a group of university students. Soc Psychiatry Psychiatr Epidemiol. 2008;43:667-72.

22. Eisenberg D, Gollust SE, Golberstein E, Hefner JL. Prevalence and correlates of depression, anxiety, and suicidality among university students. Am J Orthopsychiatry. 2007;77:534-42.

23. Waqas A, Rehman A, Malik A, Muhammad U, Khan S, Mahmood N. Association of ego defense mechanisms with academic performance, anxiety and depression in medical students: a mixed methods study.
Cureus. 2015;30:7:e337.

24. Zigmond AS, Snaith RP. The hospital anxiety and depression scale. Acta Psychiatr Scand. 1983;67:361-70.

25. Bjelland I, Dahl AA, Haug TT, Neckelmann D. The validity of the hospital anxiety and depression scale. J Psychosom Res. 2002;52:69-77.

26. Andrews B, Wilding JM. The relation of depression and anxiety to lifestress and achievement in students. Br J Psychol. 2004;95:509-21.

27. Webb E, Ashton C, Kelly P, Kamali F. Alcohol and drug use in UK university students. Lancet. 1996;348(9032):922-5.

28. Quince TA, Wood DF, Parker RA, Benson J. Prevalence and persistence of depression among undergraduate medical students: a longitudinal study at one UK medical school. BMJ Open. 2012;2:1-8.

29. Bunevicius A, Katkute A, Bunevicius R. Symptoms of anxiety and depression in medical students and in humanities students: relationship with big-five personality dimensions and vulnerability to stress. Int J Soc Psychiatry. 2008;54:494-501.

30. Woolf K, Cave J, McManus IC, Dacre JE. "It gives you an understanding you can't get from any book." The relationship between medical students' and doctors' personal illness experiences and their performance: a qualitative and quantitative study. BMC Med Educ. 2007;7:50.

31. Pais-Ribeiro J, Silva I, Ferreira T, Martins A, Meneses R, Baltar M. Validation study of a Portuguese version of the Hospital Anxiety and Depression Scale. Psychol Health Med. 2007;12:225-7.

32. Coentre RM, Figueira ML. Depression and suicidal behavior in medical students: A systematic review. Curr Psychiatry Rev. 2015;11:86-101.

33. Garlow SJ, Rosenberg J, Moore JD, Haas AP, Koestner N, Hendin H, et al. Depression, desperation, and suicidal ideation in college students: results from the American Foundation for Suicide Prevention College Screening Project at Emory University. Depress Anxiety. 2008;25:482-8.

34. Downs MF, Eisenberg D. Help seeking and treatment use among suicidal college students. J Am Coll Health. 2012;60:104-14.

35. Korszun A, Dinos S, Ahmed K, Bhui K. Medical student attitudes about mental illness: does medical-school education reduce stigma? Acad Psychiatry. 2012;36:197-204.

36. Kassam A, Glozier N, Leese M, Loughran J, Thornicroft G. A controlled trial of mental illness related stigma training for medical students. BMC Med Educ. 2011;11:51.

37. Telles-Correia D, Gama Marques J, Gramaca J, Sampaio D. Stigma and attitudes towards psychiatric patients in portuguese medical students. Acta Med Port. 2015;28:715-9. 